\title{
Primary Care Physician Migration Patterns and Their Implications for Workforce Distribution
}

\author{
Ryan Kandrack, BS ${ }^{1,2}$, Grant R. Martsolf, PhD, MPH, RN $N^{1,3}$, Rachel O. Reid, MD, MS $4,5,6$, \\ and Mark W. Friedberg, MD, MPP $4,5,6$

\begin{abstract}
1, RAND Corporation, Pittsburgh, PA, USA; ${ }^{2}$ Gillings School of Global Public Health, University of North Carolina at Chapel Hill, Chapel Hill, NC, USA; ${ }^{3}$, University of Pittsburgh School of Nursing, Pittsburgh, PA, USA; ${ }^{4}$, RAND Corporation, Boston, MA, USA; ${ }^{5}$, Brigham and Women's Hospital, Boston, MA, USA; ${ }^{6}$, Harvard Medical School, Boston, MA, USA.
\end{abstract}

J Gen Intern Med 34(7):1108-9

DOI: $10.1007 / \mathrm{s} 11606-019-04872-4$

(c) Society of General Internal Medicine 2019

\section{INTRODUCTION}

Primary care physicians are not optimally distributed within the USA, necessitating programs like the National Health Services Corps, which give physicians financial incentives to relocate to Health Professional Shortage Areas (HPSAs). ${ }^{1}$ The outcomes of such relocation incentives might depend on physicians' existing migration patterns. Previous research has found that over a 5 -year period, $20-25 \%$ of physicians move from one county to another. ${ }^{2-4}$ However, these studies did not examine the migration rate for office-based primary care physicians in particular. We sought to describe recent primary care physician migration patterns.

\section{METHODS}

Using primary care physician practice locations from the SK\&A Office-Based Provider database (a roster of office-based providers in the USA updated every 6 months by phone-verification and internet search) and data from the Area Health Resources File, we performed a descriptive analysis of physician migration between 2008 and 2013. We defined primary care physicians in SK\&A as those with the following specialties: family practitioner, general practitioner, geriatrician, internal medicine/pediatrics, internist, obstetrician/gynecologist, or pediatrician.

Among all office-based primary care physicians in the USA, we identify those who changed practice locations between 2008 and 2013. We calculated the move rate as the proportion of physicians who were in a different practice location in 2013 relative to their 2008 location. We calculated moving distances using the geodist package in Stata/SE 13.1 and categorized each move as (1) within or between counties, (2) into or out of rural counties, and (3) into or out of HPSAs. We defined rural counties as having Rural-Urban Continuum Code values 4 or greater and HPSA counties as having wholecounty primary care shortage area designation from the Health Resources and Services Administration. We conducted all data management and analysis using Stata/SE 13.1. This research

Published online March 7, 2019 was approved by the RAND Human Subjects Protection Committee.

\section{RESULTS}

Of the 124,954 office-based primary care physicians who appeared in the SK\&A database in both 2008 and 2013,

Table 1 Office-Based Primary Care Physician Migration, 2008-2013

\begin{tabular}{|c|c|}
\hline & $\begin{array}{l}\text { Proportion of all 124,954 } \\
\text { physicians }\end{array}$ \\
\hline & $n(\%)$ \\
\hline \multicolumn{2}{|l|}{ Location in 2008} \\
\hline HPSA county & $54,340(44)$ \\
\hline Non-HPSA county & $70,614(56)$ \\
\hline Rural county & $15,172(12)$ \\
\hline Urban county & $109,782(88)$ \\
\hline $\begin{array}{l}\text { Moved to a different practice site } \\
\text { between } 2008 \text { and } 2013\end{array}$ & $7918(6)$ \\
\hline Move distance & $\begin{array}{l}n \text { (\% of } 7918 \text { physicians who } \\
\text { moved) }\end{array}$ \\
\hline Move $<10$ miles & $6047(77)$ \\
\hline Move $10-20$ miles & $976(12)$ \\
\hline Move $20-50$ miles & $690(9)$ \\
\hline Move $>50$ miles & $181(2)$ \\
\hline $\begin{array}{l}\text { Moved to a different practice } \\
\text { within the same county }\end{array}$ & $6173(78)$ \\
\hline \multirow[t]{2}{*}{ Moved between counties } & 1745 (22\% of the 7918 movers) \\
\hline & $\begin{array}{l}\text { Proportion of } 1745 \text { physicians who } \\
\text { moved between counties } \\
n(\%)\end{array}$ \\
\hline \multicolumn{2}{|l|}{ HPSA movement } \\
\hline $\begin{array}{l}\text { Moved from non-HPSA county } \\
\text { to another non-HPSA county }\end{array}$ & $930(53)$ \\
\hline $\begin{array}{l}\text { Moved from non-HPSA county } \\
\text { to HPSA county }\end{array}$ & $203(12)$ \\
\hline $\begin{array}{l}\text { Moved from HPSA county to } \\
\text { another HPSA county }\end{array}$ & $203(12)$ \\
\hline $\begin{array}{l}\text { Moved from HPSA county to } \\
\text { non-HPSA county }\end{array}$ & $409(23)$ \\
\hline \multicolumn{2}{|l|}{ Urban-rural movement } \\
\hline $\begin{array}{l}\text { Moved from one urban county } \\
\text { to another }\end{array}$ & 1205 (69) \\
\hline $\begin{array}{l}\text { Moved from one rural county to } \\
\text { another }\end{array}$ & $93(5)$ \\
\hline $\begin{array}{l}\text { Moved from urban county to } \\
\text { rural county }\end{array}$ & $131(8)$ \\
\hline $\begin{array}{l}\text { Moved from rural county to } \\
\text { urban county }\end{array}$ & $316(18)$ \\
\hline
\end{tabular}


$44 \%$ were located in a HPSA county and $12 \%$ were in a rural county in 2008 (Table 1). Only 7918 (6\%) moved to a different practice site between 2008 and 2013. Of these, 6047 physicians $(77 \%)$ moved less than 10 miles, $181(2 \%)$ moved more than 50 miles, and 6173 (78\%) moved within the same county. Of the 1745 physicians who moved to a different county, only 203 (12\%) moved from non-HPSA to HPSA counties compared with 409 (23\%) who moved from HPSA to non-HPSA counties. Only $131(8 \%)$ moved from urban to rural counties compared with 316 (18\%) who moved from rural to urban counties.

\section{DISCUSSION}

Over a 5-year period, we found very little physician migration: $6 \%$ of office-based primary care physicians moved between practices, and only about $1 \%$ moved across county lines. Among those cross-county moves, most did not change HPSA or rurality status; however, among those who did change, net movement was away from rural counties and HPSAs.

We find significantly lower levels of migration compared with those of prior studies which have relied on the American Medical Association Masterfile. ${ }^{2-4}$ Previous research supports the accuracy of SK\&A geographic data relative to the Masterfile. ${ }^{5}$ There are also substantial systematic errors in the Masterfile location data as a result of physicians reporting residential addresses rather than office addresses leading to over-estimating physician supply in high-income areas and under-estimating in low-income areas. ${ }^{6}$ In contrast, SK\&A only reports practice addresses for physicians and the data are phone-verified twice per year. Future research is warranted to explore the relative utility of these databases for longitudinal physician tracking.

Our study was limited by our inability to distinguish moves occurring at the end of training (i.e., after residencies or fellowships), as we cannot identify trainee physicians in SK\&A. Further, we cannot distinguish between migration at the end of a NHSC service obligations versus baseline migration preferences; these may disproportionately contribute to the net flow of physicians out rural areas and HPSAs. In addition, the SK\&A database contains information only on office-based physicians, so our estimates may not generalize to other settings.

Our findings suggest that despite existing and long-standing financial incentives for physician relocation, and without further interventions to alter physician migration patterns to rural and underserved areas, shortages due to maldistribution of office-based physicians are likely to persist and may gradually worsen.

Funding Source: This work was funded by the Washington State Institute of Public Policy.

Corresponding Author: Ryan Kandrack, BS; Gillings School of Global Public Health, University of North Carolina at Chapel Hill, Chapel Hill, NC, USA (e-mail: kandrack@live.unc.edu).

\section{Compliance with Ethical Standards:}

This research was approved by the RAND Human Subjects Protection Committee.

Conflict of Interest: Since 2013, Dr. Friedberg has received research funding unrelated to the current work from the National Institutes of Health, the Agency for Healthcare Research and Quality (directly and via subcontract to Westat), the Patient-Centered Outcomes Research Institute via subcontract to the National Committee for Quality Assurance, the Centers for Medicare \& Medicaid Services, the Robert Wood Johnson Foundation, the Commonwealth Fund, the American Medical Association, the Washington State Institute for Public Policy, CedarsSinai Medical Center, the American Board of Medical Specialties Research and Education Foundation, the Milbank Memorial Fund, and the American Academy of PAs. Dr. Friedberg also has a clinical practice in primary care at Brigham and Women's Hospital and thus receives payment for clinical services, via the Brigham and Women's Physician Organization, from dozens of commercial health plans and government payers, including but not limited to Medicare, Medicaid, Blue Cross and Blue Shield of Massachusetts, Tufts Health Plan, and Harvard Pilgrim Health Plan, which are the most prevalent payers in Massachusetts. Dr. Friedberg also receives compensation from Harvard Medical School for tutoring medical students in health policy. All remaining authors declare that they do not have a conflict of interest.

Publisher's Note: Springer Nature remains neutral with regard to jurisdictional claims in published maps and institutional affiliations.

\section{REFERENCES}

1. Rosenthal MB, Zaslavsky A, Newhouse JP. The geographic distribution of physicians revisited. Health services research. 2005;40(6 Pt 1):1931-1952.

2. Holmes GM, Fraher EP. Developing Physician Migration Estimates for Workforce Models. Health services research. 2017;52 Suppl 1:529-545.

3. Ricketts TC. The migration of physicians and the local supply of practitioners: a five-year comparison. Academic medicine : journal of the Association of American Medical Colleges. 2013;88(12): 1913-1918.

4. Ricketts TC, Randolph R. Urban-rural flows of physicians. The Journal of rural health : official journal of the American Rural Health Association and the National Rural Health Care Association. 2007;23(4):277-285.

5. DesRoches CM, Barrett KA, Harvey BE, et al. The Results Are Only as Good as the Sample: Assessing Three National Physician Sampling Frames. Journal of general internal medicine. 2015;30 Suppl 3:S595-601.

6. McLafferty S, Freeman VL, Barrett RE, Luo L, Shockley A. Spatial error in geocoding physician location data from the AMA Physician Masterfile: implications for spatial accessibility analysis. Spatial and spatio-temporal epidemiology. 2012;3(1):31-38. 